\section{THE EARLY DIAGNOSIS AND TREATMENT OF CANCER OF THE STOMACH.*}

\author{
BY B. G. A. MOYNIHAN, M.S., F.R.C.S.,
} HONORARY SURGEON LEEDS GENERAL INFIRMARY.

A DEBATE upon the early diagnosis and the treatment of cancer of the stomach is most necessary, for the disease claims approximately 1,500 victims every year in England; it is seldom that we are enabled to do much to relieve those who suffer from it; and the cases that we have cured are so few as to be almost negligible. It is only by the close association of the physician and the surgeon, and by their united endeavours, that any hope of improvement in this lamentable state of affairs can be entertained. The opinions which I am about to express will probably not meet with the approval of all, may perhaps encounter the strong opposition of some, but they are views which I have been brought by degrees to hold firmly, and I am here to speak of the faith that is in me.

\section{Anamnesis.}

It has long been a practice of mine, in eliciting the anamnesis of pationts referred to me with any abdominal disorder, to endeavour to disentangle their thoughts from the present phase of the disease, in order to concentrate them upon the very earliest departures from health of which they have knowledge. A little persuasion, a little patience, and constant encouragement are sometimes necessary before the whole story will be told, but the time is well spent, and the inaugural symptoms, which are of the highest significance, are then disclosed. If this course be followed with patients who are subsequently shown; by operation, or autopsy, or by the later developments of their disease, to be suffering from carcinoma of the stomach, all three different types of clinical history will be elicited.

In the first the patient stoutly denies, nor can any persuasion induce him to recall, any earlier illness or suffering in connexion with the stomach. He will say that his digestion has always been of the best, and that all foods hive been alike to him, all have been taken with zest, and that "dyspepsia" or "indigestion" has never in the slightest degree troubled him. In this condition of good, even robust, health there has been a forcible and abrupt intrusion of symptoms hitherto unknown. A sudden haemorrhage from the stomach may occur, one or two pints of blood being brought up, and from that moment there appear the symptoms indicative of a gross lesion of the stomach. The anaemia which follows so free a haemorrhage persists unduly, and food, especially meats, fät or lean, becomes distasteful. A sense of uneasiness, distress, weakness (it is variously described) is felt in the epigastrium; vomiting may be repeated, weight is lost, and a palpable tumour rapidly develops in the stomach wall. As a characteristic example of this class I will quote the following cases :

Mr. F., aged 34. Sent by Dr. Mitchell, Oldham. Up to nine weeks before I saw him, on October 26th, 1908, the patient had been perfectly well. The closest examination failed to reveal any history of former trouble in the stomach His father-inany history of former trouble in the stomach. His father-inweeks before he had begun to suffer discomfort one hour after food; there was a feeling of fullness and flatulence in the epigastrium and abundant eructation of gas, which at last was almost rancid in its offensiveness. There was never severe pain only a sense of "weight and stagnation." The patient repeatedly said he felt as if there were "something in the stomach that would not move on"; and he felt that the food could not get away. Four weeks later he began to vomit, and did so every day for more than a week; then occasionally there was a day when he did not vomit, and when that was so he afterwards noticed food which had been taken the previous day in the vomited material. Vomiting had ceased for over a week before I saw him. There had never been haematemesis nor melaena. From the beginning, but especially during the last month, he had got weaker and thinner and very much paler. When I saw him he was profoundly anaemic; his face was of a white waxen appearance, and the mucous surfaces were almost bloodless. In the epigastrium I found a tumour whose upper margin was well defined, but whose lower was indefinite. The tumour moved on respiration; there was no dilatation of the stomach. The con tents showed no free $\mathrm{HCl}$; lactic acid was present. OpplerBoas bacilli were innumerable. I found on opening the abdomen there was a growth along the whole length of the lesser

1.* Renarks made in opening a discussion at the Harveian Societ of London. curvature, and that throughout the stomach there were deposits of growth resembling boiled sago grains. Glands in all directions were enlarged, and there was a very large secondary growth in the liver. He died on December 23rd, 1908. The growth in the liver had increased considerably.

Mr. J., aged 63. Sent by Dr. Malim, Rochdale: Up to August; 1907, he was perfectly well. He was a man who had led a busy life, amassed a fair fortune, and had lived carefully. There had never been any indigestion nor any abdominal
disorder of any kind. There was, in fact, as the patient said, "a clean bill of health." In August, 1907, he had a severe attack of haematemesis; he did not remember ever having vomited before, and he had never vomited since. After this he was weak and ill and very anaemic, but he gradually improved in appearance and returned to business. He had, however, lost all appetite; he could not take any meat, and soon gave up all all appetite; he could not take any meat, and soon gave up all 1908. He had the frame of a big man, but his clothes hung 1908. He had the frame of a big man, but his clothes hung
loosely upon him. He was very anaemic, and capillary vessels stood out prominently against the white background of his cheeks. He took very small quantities of soups and milk and tea. In the epigastrium a large, ill-defined tumour could be felt. Lavage and examination by test meal showed long stagnation of all the contents of the stomach, which contained blood yeast, pus, and bacteria. At the operation I found a growth involving the lesser curvature near the pylorus, and growth involving the lesser curvature near the pylorus, and,
passing behind the stomach adhering to the pancreas, it involved the greater curvature also. There were several sagolike bodies on the surface of the pyloric portion of the stomach. I performed anterior gastro-enterostomy, with slight temporary benefit.

In the second class are placed all those cases in which a clear history of chronic gastric ulcer can be obtained. In some of these cases there has been only one attack, or pos. sibly two or three attacks rapidly succeeding one another within the period of a single illness, followed by a complete abeyance, or at least a complete latency of all symptoms until the onset of the malignant disease. In other cases the patients have had a long series of attacks, in many. respects closely similar to the present one, of "indigestion." These attacks have been characterized by pain appearing always at a definite interval after food, the interval being longer or shorter according to the character of the food taken. After a solid meal the pain appears rather more slowly, but is unmistakably more severe; after a meal consisting of fluids only the pain comes more quickly, is less severe, and passes away more rapidly. The pain varies in its position, but is usually referred to the middle line, where a tender spot can generally be discovered. The left or the right costal margin may be tender, and the radiations of the pain may be to one side or another, or through to the back. Vomiting is not a frequent symptom; when it occurs it brings instant relief, and a habit of inducing it may accordingly be developed by the patient, who is confident of obtaining ease in that way. Attacks are prone to come more often in cold weather, or as a result of a chill, or by reason of increased work, worry, and anxiety. In some cases the evidences of stasis may develop, though they rarely become dominant. The patient, long accustomed to suffering, may be resigned to the restricted diet of a "chronic dyspeptic." One patient-a lady who celebrated her silver wedding a few days after I had operated upon her-had never, within the period of her husband's knowledge of her, eaten one solid meal. The foods usually taken are of the light, easily masticated, and easily propelled foods. In the history of many patients, however, there are "latent periods" during which food can be taken, if not with a keen relish, at least with better appetite and enjoyment than is usual. But after such a period there is again the breakdown, and pain in its characteristic form returns. An occasional indiscretion, even when the patient is quite well, may bring a reminder of the need for care, and certain articles of diet must be sedulously avoided at all times. Experience of repeated troubles has imposed upon the patient the necessity for care in the selection of a dietary. The "attacks" are without question due to a chronic gastric ulcer. When we operate to-day upon patients who recount these symptoms the chronic ulcer can always be found and demonstrated. After a history of repeated attacks; alike in onset, in character, duration, and relief, comes one attack at first so closely resembling all the others that it is with difficulty to be distinguished as having a special significance, but by degrees revealing a sinister importance and leading on by stages, presently to be described, to a condition clearly due to cancer. This group is indubitably the most common. Approximately, two out of every three 
cases in which carcinoma of the stomach is found in my series give a history of this kind. One or two examples may be given:

Mr. M., aged 48, sent by Dr. Wesley Smith, seen by me August 8th, 1908. The patient has been." bothered with indigestion for years." The pain has always been definitely related to the taking of food. His meals have often been hasty; he has "bolted" solid food, and the meal times have been most inregular. After special stress of work; he has often had to "give up entirely" because of an attaok of indigestion. Pain has come usually 1 , hours after food, and the food has then begun to regurgitate; and a feeling of great oppression and fullness has been relieved by belching. About an hour after food he had " miserable diseomfort," which a hot drink would often relieve. The present attaok began about Christmas, 1907, and has continued ever since. He has lost over 4 st. in weight. Recently his discomfort has only been relieved by getting the tood back. He is easy when the stomach is empty, and never at any other time. On examination, a tumour is palpable, and on slight inflation peristaltic waves are visible. Operation - October 14th, 1908. A large tumour occupying the lesser -curvature up to the pylorus, and extending down both surfaces Partial gastrectomy. The growth was malignant, and had begun in a saddle-shaped ulcer.

Mrs: A., aged 45, sent by Dr. Horsfall, Slaithwaite, seen .July 10th, 1907. The patient says that she has suffered from her stomach "all her life." When asked to be more precise, she says that she remembers very well an attack when she was -20 years old, and that was not the first. In an attack pain came about one hour after food; the pain was worse after heavy foods, but came more quickly after liquids. Vomiting at first did not occur, has since been frequent, but has always brought relief. No blood has been seen at any time. In the intervals between attacks she feels very well; the longest interval was rather more than a year in duration. The last attack began at Ohristmas, 1906. The pain was of the same character, but became by degrees more severe. Diet was restricted to fluids, but pain persisted, and recently has been almost constant. Vomiting has been frequent during the last few weeks. Ha lost in this attack $20 \mathrm{lb}$. Does not improve with the same treatment as before. I operated upon her on July 19th, 1907, and performed partial gastrectomy. There was a large prepyloric growth; a great many glands in both omenta, and the right suprapancreatic glands and the subpyloric group were especially large. The patient died in September, 1908, having had three "fits" on the two days preceding her death.

In 3 cases in my series perforation of an ulcer had occurred twenty-six, ten, and four years previously. In the first case the perforation had been of the "chronic" type, and a perigastric abscess had formed. In the others the history suggested that the perforation had been of the "subacute" type, and the conditions found at the operation lent strong support to this view.

Symptoms of Cancer.

This being the early history, what are the symptoms which are present in the final attack which proves to be due to malignant disease? The patient notices, by almost imperceptible degrees, that the relief which has formerly come for a brief period after a meal is curtailed, that pain comes more speedily or is not relieved at all. It is not long, therefore, before food is taken in lesser quantity, and becomes restricted to fluid forms alone. There is often a distaste for meat, especially for fat meats, as observers long ago noticed. The zest for food is lost entirely, and there is - often a positive repugnance to it. While the ulcer is still simple there is rarely a distaste for food; on the contrary there is often a feeling of great desire for food but experience has shown that indulgence is followed by distress or pain. I have commonly heard it said, "I could eat anything, but I dare not." In patients suffering from well-established cancer this is never heard; the cry is always that the thought of food is abhorrent, and it is difficult to persuade a patient to overcome his intolerance There is, then, little or no freedom from pain, and a sense of uneasiness, or "sinking" in the epigastrium; yet the pain is never severe, is often not a matter of complaint at all. Food which has been taken "lies heavily" on the stomach, and regurgitation of it may occur, and a nauseous bitter, but not acid, taste is noticed. There is often much flatulence and eructation of gas. There are times when the gas and the vomited matters are unendurably offensive. The lessening of the size of the stomach by the discharge - of either gaseous or fluid contents always brings relief Very early in the attack anaemia is seen; it is not, as it may have been before, the anaemia which can be attributed to a large and noticeable loss of blood; it is rather a gradually deepening pallor, the faoe seeming of a whiter colour than the rest of the body. It is not infrequent for the colour to be of the faintest yellow tinge, and the resemblance to the hue of pernicious ansemia is vers close. In all such cases there is a continuing loss of blood, as examination of the stomach contents; removed: by the tube; or of the faeces, will show: Aneemia is, perhaps, the most striking of all the signs which indicate the onset of carcinoms in the stomach. The appearance of the patient with pallid; shrunken face, and features preternaturally sharp, the skin being dry and harsh and withered, will often rouse the first suspicion of the gravity of his disease. Loss of weight is continuous; at first it, perhaps, hardly attracts attention, but as soon as note is taken of it, a steady and unchecked wasting is observed. General weakness, indif: ference to many of the affairs of life which formerly held an absorbing interest, languor and lassitude are all seen in greater, than in less, degree. Such is the complete picture seen in the majority of the cases of carcinoma. A discrimination of two distinct types can usually be found in all cases where the pyloric half of the stomach is the seat of disease. These I would designate as cases of "pyloric" and of "prepyloric" growth. In the former the symptoms almost from the first suggest the presence of a hindrance at or near the pylorus. Vomiting is among the very early symptoms, and dilatation of the stomach, with stagnation, and the periodic return of the long-delayed food, occur. These cases are recognized early, owing to the inability of the patient to take food, either solid or liquid, with comfort, and to the overt character of the cardinal symptom, vomiting. The danger is in mistaking, as I have unhappily done, on more occasions than one, the growth for a chronic ulcer. A palliative operation, gastro-enterostomy, is then performed, when : a radical operation, partial gastrectomy, is needed. In the "prepyloric" form the symptoms are such as I have already duscribed; they are general and constitational rather than local, and are, therefore, less compelling in their interest. The ulcer, and the growth which follows it, are found upou the lesser curvature away from the pylorus; the ulcer has probably been, and may often be shown to be, saddle shaped, and consequently a high degree of obstruction does not come till late. The mere presence of a growth on the lesser curvature-or, indeed, of an ulcer also-seems to do something to impede the passage of food onwards, possibly by entanglement of the nerve supply; a zone of muscle of lessened power offers obstruction in some sort, and causes both stasis and vomiting.

In the third group the patients, who are generally between 40 and 45 years of age, give a history which, in all its essential details, is identical with that in Group 2. But there is one significant omission. No history of any illness which can be referred to a structural lesion in the stomach can be elicited. The whole clinical course is comprised in the one sustained illness which, without haste but without pause, has brought the patient into. a condition of serious ill-health. The symptoms in their earlier stages are pain, which appears sooner or later after food, and is worse after solid food to such a degree that liquids soon form the whole dietary; occasional vomiting, and possibly haematemesis or rarely melaena, and loss of weight. There is nothing alarming or particularly distressing in the symptoms, but it is their persistence rather. than their prominence which finally attracts attention. Wasting anaemia and perhaps - vomiting become conspicuous, and at last it is realized that the patient is probably attacked by some serious organic disease.

At the operation carcinoma is found,-and, most important point of all, the growth, in my experience, is sometimes found to be in the site of a chronic ulcer. In this group of cases there is no suspicion, clinically, or only a very vague suspicion, that a chronic ulcer of the stomach has ever been present. It is the pathological disclosures which make it probable or certain that in many an ulcer has formed, an ulcer which at the moment of its full develop: ment has straightway become invaded by an insidious malignant process. The change which occurs in this ulcer is in every feature the same as that which is noticed in the cases in Group 2; but in these the change comes in the first life of the ulcer, in the others only after it has many times healed and as often broken down again. The following is a good example:

Mrs. B., aged 46. Sent by Dr. McLeod, Outwood. Seen by me October 10th, 1908. The patient had been perfectly well up 
to six months before. She then began to suffer pain one to one and o half hours ofter food ; vomiting occurred shortly afterwards, and always gave some relief. There was never haema. temesis. The pain gradually increased in severity, and latterly had been much worse after solid food, especially meat. At first there were periods during which she felt quite well, but lately the suffering has been continuous, and weight has gradually been lost to the extent of $11 \mathrm{lb}$. On examination there was a dilated, visibly acting stomach, and a lump the size of a hen's egg was palpable at the pyloric end of the stomach.

Operation.-The palpable tumour was seen to be a mass of malignant glands ("subpyloric" group). On the anterior surface of the stomach close to the pylorus was a hard round scar, with radiating puckers from it. Partial gastrectomy. Recovery. An examination of the specimen showed a large chronic ulcer of the stomach, at the lower part of which the edge was raised into a mass the size of a Barcelona nut. This was malignant, as also were the glands underlying it.

\section{Relation of Gastric Ulcer to Cancer.}

In the remarks I have already made I have done something more than hint at the connexion between ulcer of the stomach and cancer. Are we entitled to say that there is any proved connexion between the two? If we are, then chronic ulcer of the stomach must be ranked among the "precancerous" conditions; and if, further, the connexion be proved to be of either moderate or large frequency, cancer of the stomach is surely robbed of some of its terrors, for it is doubtless then to be enrolled among the preventable diseases. What is the evidence? In a previous paper, read before the Clinical Society of London in February, 1906, I collected and analysed all the cases of cancer of the stomach (58 in number) upon which I had operated up to July, 1905.1 In the last 22 cases a history of chronic gastric ulcer was clearly obtained in 16; in 1 case there had been a subacute perforation of an ulcer on the lesser curvature near the pylorus. In 1 case the "attack" of gastric ulcer had occurred twenty-six years before; in the interval the health had been good and digestion sound, though care had always been exercised in the matter of diet.

Almost identically the same proportion has held good for my later cases, numbering over 100 , and I am therefore in a position to say that of all patients operated upon by me for cancer of the stomach approximately two in every three have had a history of previous gastric ulcer. In the majority of those who give this history there has been a constant succession of attacks, similar in all their chief manifestations and brought about by similar causes. In the last attack the symptoms have been of a graver nature, more protracted, not amenable to the treatment, nor relieved by the drugs, which proved successful before; and by degrees it has become unmistakable that this attack is likely to prove of a far more serious character.

From the clinical point of view it is, therefore, certain that we must look for the inaugural symptoms of cancer of the stomach rarely among those whose former health has been good, often among those whose anamnesis tells sometimes of one, but, as a rule, of many attacks of "dyspepsia" or " indigestion," as they may be called. These attacks of pain come after food, are definitely related to the taking of food, are eased for a time by food, and there are also vomiting, inability to take or temporary dislike for solids, and loss of weight; the attacks, that is to say, are clearly to be referred to the presence of a chronic gastric ulcer. If, therefore, we are to concentrate our attention upon the early symptoms of cancer of the stomach, it is the patient whose stomach has long been a source of trouble to him that must chiefly engage our attention. But it is necessary to say that this patient, who is, so to speak, the most promising candidate for carcinoma of the stomach, can be prevented from developing this horrible affliction by a timely attention to the earlier simple disease. Cancer of the stomach, if it foljows in the majority of cases upon chronic ulcer of the stomach, is so far, and in such numbers, a preventable disorder. In the surgical treatment of chronic gastric ulcer by the performance of gastro-enterostomy, or of Rodman's operation, may be the means of destroying the chances of a late malignant change from an early simple condition. It has often been said that "the onset and persistence of dyspepsia in a man over 40 years of age, who had previously enjoyed good health is a suspicious circumstance" pointing probably to the onset of carcinoma. I have found that in such cases the disease is more often simple than malignant, and that the lesion found is more frequently duodenal than gastric.

I am only too well aware of the doubt, even perhaps of the hostility, with which the suggestion has been received that ulcer of the stomach and cancer stand often in the relationship I have indicated. But impartial inquiry into. the history of a long series of cases will support, I know well, the views I have expressed. Clinically there can be no longer any substantial doubt of the connexion. Is. there any valid pathological evidence to support the belief which clinical experience has stimulated? I have no. hesitation in saying that the pathological evidence now available supports fully the contention I have stated. In what manner should we expect that evidence to be obtained? I venture to answer that it could only beobtained from specimens examined in an early stage of the disease, at a time when the primary simple disease and the later cancerous change can be seen together. It is, then, necessary also to show that the former condition is earlier than the latter. A moment's thought will con. vince one of the truth that a specimen of this kind is hardly to be found upon the post-mortem table in the body of one who has succumbed at last to the steady and unchecked extension of a malignant growth. The only specimens which are likely to furnish valid evidence must. be obtained by operation. The best of these specimens. are found when a chronic ulcer, as the appearance suggests, is removed by Rodman's operation. Though no suspicion of malignancy may have crossed the surgeon's mind, the pathological examination will disclose the undoubted. evidence of early malignant disease in an area where the. ancient marks of simple disease are plainly to be seen. In. this connexion one cannot but offer a tribute to the remarkable work which has been done in the clinic of $\mathrm{Dr}$. W. J. Mayo and Dr. C. H. Mayo at Rochester. 1 had the privilege a few months ago of seeing the specimens of partial gastrectomy removed by them, and of having the pathological conditions demonstrated to me. No one who has seen the evidence there produced doubts any more: that cancer of the stomach is frequently the offspring of an early simple disease. Dr. W. J. Mayo ${ }^{2}$ has recorded the fact that, in 180 cases of resection of the stomach, cancer was demonstrated to have sprung up in the base of an ulcer in 97, that, is in 54 per cent. My own experience supports this statement fully; indeed I have myself found the percentage even a little higher in my recent cases.

The connexion between chronic ulcer of the stomach and carcinoma I hold, therefore, to be established so far as Group 2 is concerned. Is there any relationship between the acute cases of cancer of the stomach, cases which seem to have in them something akin to an acute infection, and ulcer? There is no history of chronic ulcer in this class of case; the disease seems to begin acutely and to spread rapidly; in my own work no permanent relief has ever followed operative treatment, and the benefit obtained by the palliative operation of gastro-enterostomy is too often quite inconsiderable. Recently $I$ have come to believe it possible that in these cases also an ulcer may be the starting point of the malignant process. The ulcer in such cases is of the "acute" type; one or more "haemorrhagic erosions" are present, and in these cancer is deposited and spreads there with the most intense rapidity.

If carcinoma should be conclusively proved to be the final change in the Jong series of changes which have led up to and established a chronic ulcer in the stomach, is it not in this case merely repeating the experience we have gained of its habits in other parts of the body? We know how frequently cancer of the tongue develops as a last change in a series of conditions all of which are simple. It is only the bare truth to say that cancer almost never develops in a tongue previously healthy; where a maljgnant ulcer is present other changes are seen around it, and these have been present, always for months, often for years. Cancer is there only a local exaggeration of or a later change in a condition of things distributed. over other parts, or over the whole of the tongue. It is the same with the lip, and with the ulceration of old scars due to burns. The development of cancer on the corona as a result of the irritation of smegma retained by a too long and too tight prepuce was pointed out more than a century ago by the first William Hey of Leeds. In the breast the transformation from chronic mastitis ta 
malignancy is no longer doubted. In the gall bladder it is commonly seen. And instances might easily be multiplied. Surely the one thing of which surgeons feel sure in respect of cancer is that it seems most often to occur in those parts where mild irritation has long been present.

\section{Exploratory Incision.}

A review of the cases which have been under my own care has convinced me that though the history, especially in so far as it tells of former attacks of chronic gastric ulcer, may awaken a keen suspicion as to the presence of a carcinoma in the stomach, and though all the contribu. tory evidence to be derived from the chemical examination of the stomach contents may go towards a confirmation of the diagnosis, there is only one means of making an assured diagnosis in an early stage. An inspection of the parts, and this alone, and that indeed not always, can give us the information upon which a probable diagnosis can be made. It is necessary for us to realize that by any other methods than this one a positive diagnosis of cancer in the stage when it is capable of successful treatment is almost impossible. If the patients who are suffering from this most insidious and most terrible disease are to have any fuller prospect of relief, or of cure, the use of the exploratory operation must be greatly increased. I deprecate more strongly, I believe, than most surgeons the adoption of the "exploratory incision"; but every argument and all experience show that in cases of carcinoma of the stomach no other method than this offers any slenderest hope for the betterment of the present deplorable condition of affairs. But before we are entitled to advise any patient to undergo this operation we must be confident that there is a well-grounded suspicion that some condition not admitting of remedy by any other than surgical means will be found.

\section{Indications for Operation.}

I think that an operation should be advised in the following circumstances:

(a) In all cases of chronic gastric ulcer. The recent experience of surgeons has shown that a diagnosis of chronic gastric ulcer can be made with great accuracy, and that not only the presence but also the position of the ulcer can be accurately predicted. When repeated "attacks" occur it is idle to consider any other than operative treatment, for nothing else can give permanent relief. In any attack occurring in a patient over 40 years of age the need for surgical intervention is becoming argent.

(b) When gastric stasis is present. This is a condition the existence of which is easily determined. If there are symptoms suggesting structural disease in a stomach incapable of emptying itself completely in from ten to twelve hours, then the conditions which exist are mechanical, and can be remedied by none other than mechanical means.

(c) When a tumour is present. The tumour may be simple or malignant, but research is better conducted by inspection than by any other means at our disposal.

In these three conditions medical treatment may do something to relieve, it can do nothing to cure. There is accordingly no reason for delay in advocating operation. If this is done, and done early, many cases of carcinoma that now drift quietly into the inoperable stage may be saved.

The position seems now to be this-that there are no signs or symptoms clearly indicative of the presence of gastric cancer; there is no refinement of clinical inquiry nor any endowment of clinical acumen which will enable a confident diagnesis to be made in an early stage; inspection of the stomach during an operation carried out when definite faults in its working are known will permit of the early discovery, or of the prevention of a certain proportion of the cases of cancer. The surgeon must not ask the physician for a sign which will reveal the presence of this disease to him, but he can and should require that those conditions which are only to be remedied by operative measures should be referred to him not in their advanced or terminal stages, but at the earliest moment of their recognition. The success which has followed the surgical treatment of gastrie disorders justifies this simple request.
Chemical Analysis of Gastric Contents.

A point which cannot be ignored in any discussion upon the early recognition of cancer of the stomach has reference to the condition of the stomach contents. Much has been written with regard to the value of a chemical examination of the stomach contents in cases of gastric carcinoma. It is my practice to have all stomach cases examined as a matter of routine, and I place some reliance upon the results so afforded. But it is necessary that more examinations than one should be made, and that the circumstances should be changed in some of the examinations. The fluids removed from the stomach after several hours of fasting, after a test meal preceded by lavage, and after a meal consisting chiefly of albumens should be examined. The characteristic result in cases of cancer shows absence of free $\mathrm{HCl}$, a diminished total acidity, the presence of lactic acid, and the presence of Oppler-Boas bacilli. Briefly stated, my opinion is that the early diagnosis of carcinoma of the stomach receives only the slenderest help, if indeed it receives any, from those examinations; whereas, in the later cases, a suspicion of malignancy receives strong confirmation if the characteristic conditions I have named are found.

Conclusions.

I would endeavour to sum up my knowledge of cancer of the stomach, as revealed to me by a study of the cases which have come to me for surgical treatment, in the following propositions:

1. Cases of cancer of the stomach when examined in regard to their previous history may be divided into three groups: (a) Cases, generally acute, in which the symptoms appear suddenly and progress rapidly; the whole history may be confined within a space of four to nine.months. (b) Cases in which there is a history of one ancient attack, or of repeated attacks, due undoubtedly to the presence of a chronic gastric ulcer. (c) Cases in which there is no previous history of gastric ulcer; in some of them a condition of "ulcus carcinomatosum" may be found.

2. The acute cases are not seldom ushered in by an attack of severe haematemesis, with or without melaena. It is possible that such copious bleeding is dependent upon multiple haemorrbagic erosions.

3. The importance of a history of repeated attacks of indigestion, alike in their origin, course, and termination, cannot be exaggerated. Such attacks are due to a chronic gastric ulcer, which at last becomes malignant.

4. Cancer of the stomach, in so far as it depends upon a chronic ulcer for its origin, is a preventable disorder. It is probable that two-thirds of the whole number of cases may be so classed.

5. The final attack is distinguished from former attacks by its lingering character, its rebellion against the treatment, dietetic and medicinal, which has proved helpful before, but chiefly by the presence of a profound distaste for food, anaemia, and a progressive loss of weight.

6. The chemical examination of stomach contents is of little or no value in so far as early diagnosis of carcinoma of the stomach is concerned. In the later cases, when a possible diagnosis of malignancy is made on the clinical evidence, the results of repeated chemical analyses of the stomach contents afford additional evidence of considerable value.

7. Surgical treatment should be advised in all cases of stomach disorder where there is obstruction, stasis, or tumour, and in all cases of chronic ulcer; in this way early cases of carcinoma will be found, and radical treatment will be possible.

8. There are no symptoms, and there are no signs which, individually or collectively, permit of an assured diagnosis of cancer of the stomach in an early stage. In cases there there is grave suspicion an exploratory operation should be advised. Such operations should be practised to enable a diagnosis to be made in an early stage, not to confirm an almost certain diagnosis in a hopeless stage.

The surgical treatment of cancer of the stomach is now based upon sound principles, as a result of the work of many labourers in different fields. When the growth is seated at or near the pylorus, or along the lesser curvature of the stomach (and these are the cases we are chiefly considering), the anatomical and pathological investigations have indicated certain essentials to be observed in order that the whole growth, and the lymphatic area in 
connexion with it, may be eradicated in accordance with those principles now generally held to be necessary in dealing with any form of carcinomatous disease.

After a study of all the factors, we are in a position to lay down the lines upon which an operation for the removal of a malignant growth beginning in the pyloric region of the stomach should be based. It is essential that the whole growth should be taken away, and such a margin beyond the visible and palpable tumour as shall ensure that the outlying nodules are within the lines of section; that all the lesser curvature, that one-half of the greater curvature, and that an inch at least of the duodenum should be removed; that all the "primary" glands at least should be taken (these are the lower and upper coronary, the right paracardial, the suprapyloric, the right suprapancreatic, the right gastro-epiploic upper and lower, and the retropyloric). The removal of all these parts is possible, and therefore the somewhat mournful view of the possibilities of the surgical treatment of cancer of the stomach taken by several writers are not justified. The difficulties to be encountered will chiefly lie in the removal of the right suprapancreatic glands, but that these difficulties are exaggerated is, I think, quite certain. In several cases I have, by using the "gauze stripping" method, removed the glands without any injury either to the hepatic artery or to the pancreas.

The following are the steps of the operation, as briefly outlined as possible:

1. The free opening of the abdomen in or near the middle line; the inspection of the parts; the packing of swabs around the area to be engaged in the operation, so as to avoid any soiling of the parts. Nothing except the viscera at the moment engaged in the operation should be pisible.

2. Preliminary ligature of the pyloric, gastro-duodenal, and left gastro-epiploic arteries (not the coronary), division of the gastro-hepatic omentum close to the liver.

3. Division of the duodenum between clamps, and the use, on the distal side, of a suture to close the duodenum by infolding. On the proximal side the exposed mucosa is well seared with the cautery, and a stitch taken round the clamp to prevent it slipping.

4. Ligature of the gastro-hepatic omentam below all glands in the greater curvature. The most important point is now to see that the middle colic artery is not wounded. The omentum is ligatured up to a point just beyond the middle of the greater curvature, so that all glands are removed.

5. The stomach is now turned well over to the left and the coronary artery ligatured at its origin from the coeliac axis. At once the lesser curvature is freed, and the stomach can be pulled lower. In this way all the coronary glands remain with the stomach.

6. Performance of posterior gastro-enterostomy. This is done before the stomash is cut away, being then far easier.

7. Division between clamps of the stomach from the oesophagus at its right margin to a point a little to the left of the middle of the greater curvature.

8. Cauterization of the exposed mucosa of the stomach and closure of the cut end of the stomach by a double suture.

9. Toilet of the peritoneum and closure of the parietal wound.

The size of the growth at or near the pylorus has no influence upon the extent of the resection. For the very smallest growth a resection to this extent is nesded. If the growth invades the body of the stomach it may involve the removal of all of the stomach but the isolated area, after the manner described by me several years ago.

$$
\text { REFERENCES. }
$$

1 British Medical Jodrnal, 1906, i, p. 370. 2 Annals of Surgery, 1908 xlvii, p. 889 .

A COMMUNICATION which has reached our hands records the aspirations formally expressed at the annual meeting on March 2lst of a body entitled l'Association médicale internationale pour aider à la suppression de la Guerre. This, as we have mentioned on a previous occasion, is peace society, claiming to be both international and medical, and having its head quarters at 25, Rue des Mathurins, Paris. The only "vœu" of a novel character was a hope that the progress of science repre sented by aëro-navigation will not be turned to the púrposses of war.

\section{ON THE SURGICAL TREATMENT OF GASTRIC ULCER, ITS COMPLICATIONS} AND SEQUELAE.

\author{
With Sixty Inlustrative Cases."
}

By JOHN MARNOCH, M.A., M.B., C.M.ABerd., SURGEON TO, AND LECTURER ON CLINICAL SURGERY AT, THE ABBRDEEN ROYAL INFIBMARY.

OF all the advances in modern surgery none is more striking than that which has taken place in the treatment of gastric ulcer. Patients suffering from this disease, or some of its dire results, need no longer drag out the miserable existence they used, for surgery holds out every hope of restoring them to good health. During the last seven years it has been my lot to operate upon 60 cases of gastric ulcer, its complications or sequelae, and it is proposed in the present paper to give some account of them. The various conditions met with have been :

(a) Active ulcer of the stomach, with and without adhesions to neighbouring viscera.

(b) Cicatrized ulcer, with and without adhesions.

(c) Hour-glass contraction of the stomach.

(d) Subphrenic abscess.

(e) Tumour after perforation of the stomach.

$(f)$ Perforating ulcer of the stomach.

The operative procedures adopted for the relief of the above-mentioned conditions may be divided into two main groups, namely, deliberate operations and emergency operations. They will be dealt with in this order.

\section{A.-Deniberate Operations.}

The deliberate operations have been :

1 case of ligature of ulcer.

1 case of pyloroplasty.

1 case of excision of ulcer and suture.

2 cases of drainage of subphrenic abscess.

1 laparotomy for tumour after perforation.

34 gastro-enterostomies, alone or combined with other operations.

1 case of gastro-gastrostomy.

1 case of lateral anastomosis.

The case of ligature of ulcer occurred among the earlier operations, and was performed on November 16th, 1901, in a young woman, 21 years of age, in whom an ulcer the size of a sixpence was found on the posterior wall of the stomach, at the extreme cardiac end, close to the lesser curvature. Here the ulcerated surface was invaginated by two layers of Lembert sutures, after which an opening was made in the anterior wall, the invaginated ulcer seized with forceps, pulled up, and a ligature applied beyond the base of the ulcer, the opening in the anterior wall being thereafter closed. The case did remarkably well and remained so for several years, after which she was lost sight of. On account of the awkward situation of the ulcer, the method of treatment mentioned was deemed safer than excision and suture.

In one case of cicatrized ulcer of the pylorus in a female patient, also one of the earlier cases, a pyloroplasty was performed. Here, although distinct improvement followed the operation, the result I am satisfied, would have been better had gastro-jejunostomy been done.

In a male patient it was found that an ulcer the size of a two-shilling piece on the anterior wall of the stomach close to the greater curvature had contracted an adhesion to the abdominal wall well down in the left lumbar region. On breaking down the adhesions it was discovered that the ulcer had eaten through the stomach walls completely, its base being formed by the parietal peritoneum. In this case the margin was excised and the gap on the stomach wall sutured. On the completion of tinis operation, the stomach receded up into the abdomen and lay so naturally that no further operative procedure was deemed necessary. The opcration was performed in January, 1905, and I believe the patient has had no further stomach trouble.

Two cases of subphrenic abscess following perforation of a gastric ulcer were met with. The first, a young married woman, was so bad when put upon the operating table that the administration of a general anaesthetic was out of the question, and the drainage, which was by the transpleural route, was under local anaesthesia. Although she caused grave anxiety for a few days, she ultimately recovered

* Read at the November meeting of the Aberdeen Medico-Chirurgical Society. 